\title{
Covid-19 Through Brazilian Courts: The Deserving and the Undeserving Vulnerable - CORRIGENDUM
}

\author{
Luciano Bottini Filho
}

https://doi.org/10.1017/glj.2021.55, Published by Cambridge University Press, 15 September 2021

Keywords: Covid-19; right to health; vulnerability theory; litigation; Brazil

The authors apologise that upon publication of this article, the paragraphs below (from the section A. Vulnerability Theory as a General Legal Principle, p. 1101) refer twice to the name of Freeman when they should in fact refer to Fineman:

"As proposed by Freeman, vulnerability is a human condition beyond identity, departing from a discrimination approach to formal equality, in a universalism that transcends categories such as race and class. ${ }^{12}$ This section argues that the post-identity stance of vulnerability theory is both helpful and limiting in the pandemic and while it can free policies of a set category of vulnerable groups, it can be misunderstood and dilute identity-based claims.

In brief, for Fineman's vulnerability theory, what distinguishes each person is the resources and effective capacity to endure adversity. Freeman argues for a "responsive State" to allocate resources according to the levels of resilience needed to compensate for the vulnerability strengthened by institutions and society. ${ }^{13}$ This view attempts to steer clear of identity concepts by referring to complexity-how different factors converge to each individual embodied or embedded forms of vulnerability-and particularity-how this complexity materializes individually. Complexity and particularity could be easily taken as identity, but Fineman wants to use vulnerability foremost as a universal principle."

Corrected text:

"As proposed by Fineman, vulnerability is a human condition beyond identity, departing from a discrimination approach to formal equality, in a universalism that transcends categories such as race and class. ${ }^{12}$ This section argues that the post-identity stance of vulnerability theory is both helpful and limiting in the pandemic and while it can free policies of a set category of vulnerable groups, it can be misunderstood and dilute identity-based claims.

In brief, for Fineman's vulnerability theory, what distinguishes each person is the resources and effective capacity to endure adversity. Fineman argues for a "responsive State" to allocate resources according to the levels of resilience needed to compensate for the vulnerability strengthened by institutions and society. ${ }^{13}$ This view attempts to steer clear of identity concepts by referring to complexity-how different factors converge to each individual embodied or embedded forms 
of vulnerability - and particularity_how this complexity materializes individually. Complexity and particularity could be easily taken as identity, but Fineman wants to use vulnerability foremost as a universal principle."

\section{Reference}

Bottini Filho, L. (2021). Covid-19 Through Brazilian Courts: The Deserving and the Undeserving Vulnerable. German Law Journal, 22(6), 1098-1114. doi: 10.1017/glj.2021.55

Cite this article: Filho LB (2021). Covid-19 Through Brazilian Courts: The Deserving and the Undeserving Vulnerable CORRIGENDUM. German Law Journal 22, 1661-1662. https://doi.org/10.1017/glj.2021.65 